\title{
Arrangement of the Highly Reiterated DNA Sequences in the Centric Heterochromatin of Drosophila melanogaster Evidence for Interspersed Spacer DNA
}

\author{
R. Kram, M. Botchan and J. E. Hearst \\ Department of Chemistry \\ and \\ Group in Biophysics \\ University of California \\ Berkeley, Calif. 94720 U.S.A. \\ (Received 30 June 1971)
}

\begin{abstract}
We have investigated the arrangement of the highly reiterated centromeric DNA sequences in Drosophila melanogaster by studying the physical properties of sequences obtained after the hydroxyapatite isolation of rapidly renaturing molecules. It was found that the fraction of material recovered as partially renatured varied with the molecular weight of the starting material, although conservative length corrections on the chosen $C_{0} t$ values were made. On banding in a $\mathrm{CsCl}$ gradient a bimodal distribution for the renatured molecules was found. This bimodal distribution was also sensitive to the molecular weight of the single strand material. The peaks were shown to consist of respectively:h.a.r.r.DNA $\dagger$ sequences and renatured h.a.r.r.DNA sequences with attached unrenatured "spacer" sequences. From melting curve data, RNA-DNA hybridization and kinetic analysis other explanations for the increased yield and bimodal distribu. tion of the renatured molecules could be ruled out. Computer simulation of a random shear process on a DNA sequence which alternates an h.a.r.r.DNA sequence from one to three times larger than the spacer sequence can be seen to fit the experimental situation. We conclude that the constitutive heterochromatin is composed of blocks of extremely simple sequences stretching from 1.5 to 6 million daltons interspersed by a more complex sequence of molecular weights of approximately 2 to 4 million daltons. A similar interspersion of sequences for tho mouso satellito DNA was found, though proliminary data suggest that the stretches of mouse satellite may be much longer. The occurrence of a more complex DNA at this locus of the Drosophila chromosome raises some interesting possibilities for both the genetic potential of this area and for chromosomal "housekeeping" functions.
\end{abstract}

\section{Introduction}

An increasing number of organisms have recently been shown to contain a class of DNA whose small sequence complexity and high concentration per genome allow them to renature extremely rapidly with $C_{0} t_{1 / 2}$ of less than $10^{-2}$ (Waring \& Britten, 1966; Flamm, Walker \& McCallum, 1969b; Votavova, Sponar \& Sormova, 1970;

$\dagger$ Abbreviation used: h.a.r.r.DNA; hydroxy-apatite isolated rapidly renaturing DNA. "Pure h.a.r.r.DNA" refers to h.a.r.r.DNA isolated from extensively sheared DNA (mol. wt. 200,000), in order to free the highly reiterated sequences from attachment to less redundant or "unique" DNA. 
Botchan, Kram, Schmid \& Hearst, 1971). Often these sequences can be resolved, using buoyant density centrifugation techniques, as a satellite. Nuclear satellite DNA's have proven very useful in providing purified samples of the most reiterated DNA sequences in the investigated genomes. Those studies have, however, exclusively focused on physical and biochemical characterizations of these sequences, as independent from the remainder of the genome.

The arrangement of spacer sequences between ribosomal cistrons in the nucleolus (Birnstiel, Speirs, Purdom, Jones \& Loening, 1968) emphasizes the importance of obtaining similar information on the organization of the satellite-type sequences in the centric heterochromatin (Pardue \& Gall, 1970; Jones \& Robertson, 1970; Rae, 1970; Hennig, Hennig, \& Stein, 1970; Botchan et al., 1971).

It was the purpose of these investigations to shed light on this problem and our previous studies (Botchan et al., 1971) indicated that Drosophila melanogaster is a suitable organism to use for this work. We have reported the occurrence in this genome of highly reiterated DNA sequences with a complexity similar to that of mouse satellite. These sequences have been localized by in situ hybridization in a discrete region within the chromocenter of the polytene chromosomes of the salivary gland. Although the $\mathrm{G}+\mathrm{C}$ composition of these highly redundant sequences is sufficiently lower than that of the remainder of the nuclear DNA so that resolution of this DNA as a light satellite in a density gradient would be expected, such a satellite is not observed in nuclear DNA preparations with molecular weights greater than $8 \times 10^{6}$ daltons. The highly redundant sequences have been shown to be concentrated in the light portion of the main band at densities 0.003 to $0.008 \mathrm{~g} / \mathrm{cm}^{3}$ greater than where the pure rapidly renatured h.a.r.r.DNA sequences band. This suggests their association with a $\mathrm{G}+\mathrm{C}$-richer component intercalated between the $\mathrm{A}+\mathrm{T}$-rich h.a.r.r.DNA sequences.

The alternatives to be considered are the following: does all the highly reiterated DNA on each chromosome occur in one single block or does it come in segments

Model A

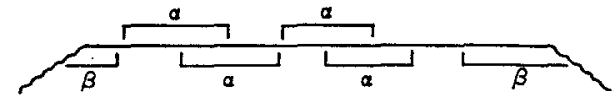

Model B

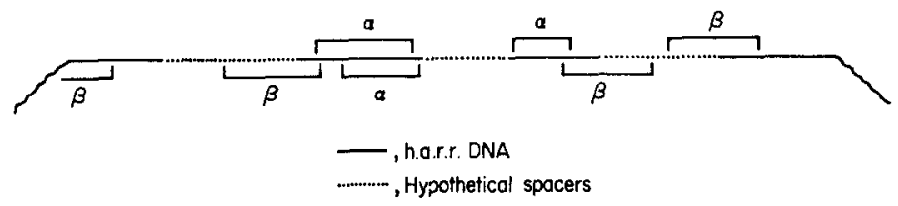

FIC. 1. Two abstract models for the arrangement of the highly reiterated DNA of the centric heterochromatin. In model A, the entire h.a.r.r.DNA on each chromosome occurs in a single block. In model B, the h.a.r.r.DNA sequences are spaced by another variety of DNA sequences. Dashed lines, h.a.r.r.DNA sequences; dotted lines, hypothetical spacers. Two types of fragments are generated by cut sizes of a given length: $\alpha$, pure h.a.r.r.DNA fragments and $\beta$, fragments containing both h.a.r.r.DNA and spacer sequences. 
spaced by segments of another variety of DNA sequences, and in this case, what are the relative sizes of both kinds of segments? The experimental approach can be described in terms of Figure 1. The highly reiterated chromocentric DNA represents $8 \%$ of the $D$. melanogaster haploid genome, which is $10^{8}$ base pairs long, i.e. $6 \times 10^{10}$ daltons. Consequently, each chromosome could contain, on the average, $10^{9}$ daltons of this type of sequence. The two possible situations can be distinguished by examining the physical properties of the isolated renatured fragments as a function of the molecular weight of the starting unfractionated nuclear DNA preparation. If one considers cut sizes small relative to $10^{9}$ daltons, model A will essentially generate $\alpha$-type fragments whereas the h.a.r.r.DNA containing fragments produced by model $B$ includes $\beta$-type fragments as well as the $\alpha$-type. $\beta$-type fragments can be distinguished from $\alpha$ by a variety of physical techniques.

Our results, analyzed by comparison with computer generated models, provide evidence for the interspersed arrangement depicted in model $B$.

This finding bears significance pertinent to the possible specificity of centromeric involvement in chromosome housekeeping and to the genetic coding potential of this complex region of the genome.

\section{Materials and Methods}

\section{(a) Preparation of DNA}

D. melanogaster DNA was prepared from postgastrula to prelarva embryos, using a modification of the procedure of Ritossa \& Spiegelman (1965).

The embryos were dechorionated in $3 \%$ sodium hypochlorite for $1 \mathrm{~min}$ and washed with $70 \%$ ethanol. They were hand homogenized at $4^{\circ} \mathrm{C}$ in $0.05 \mathrm{M}$-Tris, pH $7.6 ; 0.025$ $\mathrm{M}-\mathrm{KCl}, 0.005 \mathrm{M}$-magnesium acetate and $0.35 \mathrm{M}$-sucrose to produce cells, which were filtered twice through 280 mesh nylon screen cloth. The cells were homogenized to produce nuclei which were pelleted by a 10 -min centrifugation at $600 \mathrm{~g}$ in the cold. In early experiments, DNA was extracted immediately from this crude nuclear pellet. In most experiments, the nuclear pellet was subsequently resuspended in $2.2 \mathrm{M}$-sucrose and centrifuged for $1 \mathrm{hr}$ at $45,000 \mathrm{~g}$. The purified nuclei were resuspended in $0 \cdot 1 \mathrm{M}$-EDTA, pH $8 \cdot 2,0 \cdot 15$ $\mathrm{M}-\mathrm{NaCl}$ and the solution was made $2 \%$ in sodium dodecyl sulfate. After a 20 -min incubation at $60^{\circ} \mathrm{C}$, the lysate was made $1 \mathrm{M}$ in sodium perchlorate, incubated at $60^{\circ} \mathrm{C}$ for $10 \mathrm{~min}$, cooled to room temperature and extracted with an equal volume of chloroform-isoamyl alcohol (24:1). The emulsion was broken by centrifugation at $4^{\circ} \mathrm{C}$ for $5 \mathrm{~min}$ at $12,000 \mathrm{~g}$. The extraction was repeated once and the DNA precipitated from the aqueous phase by the addition of 1 vol. ethanol. The precipitate was collected on a glass rod, washed in ethanol-EDTA buffer $(2: 1)$ and resuspended in 0.01 SSC +5 mM-EDTA (SSC is 0.15 $\mathrm{M}-\mathrm{NaCl}, 0.015 \mathrm{M}$-sodium citrate). After dissolution in the cold room with gentle agitation, the solution was adjusted to $1 \times \mathrm{SSC}$, digested for $3 \mathrm{hr}$ at $37^{\circ} \mathrm{C}$ with heat treated RNase (Calbiochem, $150 \mu \mathrm{g} / \mathrm{ml}$.), $1 \mathrm{hr}$ with $\alpha$-amylaso (Calbiochem, $150 \mu \mathrm{g} / \mathrm{ml}$.) and finally 4 $\mathrm{hr}$ with $0.5 \mathrm{mg}$ pronase $/ \mathrm{ml}$. (Calbiochem, self-digested for $2 \mathrm{hr}$ in $0.1 \mathrm{M}$-Tris, $\mathrm{pH} 7.2$, at $37^{\circ} \mathrm{C}$ ). The mixture was extracted with phenol in the cold until the disappearance of protein interphase and reprecipitated with ethanol. After redissolution as described above, the remaining polysaccharides were removed by centrifugation at $45,000 \mathrm{rev} . / \mathrm{min}$ for 30 $\min$ in the SW50 rotor.

Contamination with either bacterial or yeast nucleic acid was ruled out because ${ }^{3} \mathrm{H}$ labeled whole Escherichia coli and yeast cells added to the starting material did not result in the recovery of any labeled DNA in the final preparations.

\section{(b) Denaturation and renaturation of $D N A$}

DNA samples were dialyzed against 0.05 M-phosphate buffer, pH 6.8. Eight parts of the DNA solution at room temperature were added to one part of $1.0 \mathrm{~m}-\mathrm{NaOH}$. After 10 min, 10 parts of warm water were added and the solution was equilibrated to $60^{\circ} \mathrm{C}$. One 
part of warm $2 \cdot 0 \mathrm{M}-\mathrm{NaH}_{2} \mathrm{PO}_{4}$ was then added to neutralize the solution of renaturated DNA. The final phosphate concentration at which renaturation occurred was thus $0 \cdot 12$ M-phosphate and the temperature $60^{\circ} \mathrm{C}$.

\section{(c) Hydroxyapatite fractionation}

After renaturation at $60^{\circ} \mathrm{C}$ in $0.12 \mathrm{M}$-phosphate buffer, $\mathrm{pH} 6.8$, for the appropriate $C_{0} t$, the DNA was poured into a slurry of hydroxyapatite in the same buffer. The elution was performed stepwise at $70^{\circ} \mathrm{C}$ with $0.12 \mathrm{M}, 0 \cdot 16 \mathrm{~m}$ and $0.3 \mathrm{~m}$-phosphate buffers, pH 6.8 , using the procedure of Flamm et al. $(1969 a, b)$. Elution of double-stranded DNA with $0.45 \mathrm{M}$ phosphate buffer in place of 0-3 M-phosphate did not alter our results.

\section{(d) DNA renaturation kinetics}

The reassociation kinetics were studied by following the absorbance changes at $260 \mathrm{~nm}$ in a Cary 15 spectrophotometer equipped with a water-jacketed quartz cell connected to two water baths in parallel. One bath was kept at $95^{\circ} \mathrm{C}$ and the other at $60^{\circ} \mathrm{C}$. The DNA samples had been sheared to a single strand molecular weight of 100,000 to 150,000 daltons and extensively dialyzed against $0.12 \mathrm{M}$-phosphate buffer. After denaturation at $95^{\circ} \mathrm{C}$ for $5 \mathrm{~min}$, the water bath at $60^{\circ} \mathrm{C}$ was connected to the cell at time zero. Temperatures in the cell were measured with a copper constantin thermocouple which showed that thermal equilibrium was reached in 20 sec.

\section{(e) Molecular weight determinations by sedimentation velocity}

The molecular weight of single stranded DNA was determined from the alkaline sedimentation coefficient $S_{20, w}^{\mathrm{pH} 13}$, which was measured by boundary sedimentation in 0.9 M-NaCl-0.1 M-NaOH. Molecular weights were calculated, using the equation $S_{20, w}^{0}=$ $0.0528 M^{0.400}$ from Studier (1965).

\section{(f) Density gradient equilibrium sedimentation}

All runs were performed at $\mathrm{pH} 6.8$ in 0.12 M-phosphate buffer at $35,000 \mathrm{rev} . / \mathrm{min}$ in $\mathrm{CsCl}$ solutions. Titanium double sector centerpieces (Gray \& Hearst, 1968) were used. Generally $48 \mathrm{hr}$ were allowed for the attainment of equilibrium.

All buoyant densities are quoted relative to a standard value of 1.710 for $E$. cali DNA. The buoyancy density gradient used to calculate density differences between bands was determined from the relation.

$$
\left(\frac{\partial \rho}{\mathrm{d} r}\right)_{\text {buoyancy }}=9 \cdot 35 \times 10^{-10} \omega^{2} \bar{r}
$$

according to Schmid \& Hearst (1971).

\section{(g) In vitro preparation of ${ }^{3} \mathrm{H}$-labeled complementary $R N A$}

Complementary RNA was synthesized by in vitro transcription with $E$. coli polymerase following the procedure of Burgess, using $\left[{ }^{3} \mathrm{H}\right] \mathrm{ATP},\left[{ }^{3} \mathrm{H}\right] \mathrm{CTP}$, and $\left[{ }^{3} \mathrm{H}\right] \mathrm{UTP}$ (spec. act. $=$ $20.5 \mathrm{Ci} / \mathrm{m}$-mole, from Schwarz BioResearch. The reaction mixture $(0.25 \mathrm{ml}$.) contained $10 \mu \mathrm{g}$ of enzyme (holoenzyme), $7 \mu \mathrm{g}$ of primer DNA, $100 \mu \mathrm{Ci}$ of each ATP, CTP, and UTP and 50 nmoles of GTP. The reaction was carried out at $37^{\circ} \mathrm{C}$ for $30 \mathrm{~min}$. The reaction mixture was treated with $20 \mu \mathrm{g}$ of DNase I (Worthington DPFF) for $1 \mathrm{hr}$ at $37^{\circ} \mathrm{C}$. Unlabeled yeast carrier RNA (200 $\mu \mathrm{g}$ ) was added and the mixture extracted twice with phenol-sodium dodecyl sulfate $1 \%$. The aqueous phase was passed over a column of Sephadex G50 and acid-precipitable counts from the run off peak were pooled. The RNA was further purified by passage through a nitrocellulose filter. The calculated specific activity was $9.8 \times 10^{7}$ disintegrations $/ \mathrm{min} / \mu \mathrm{g}$.

\section{(h) Hybridization procedure}

After alkali denaturation, neutralization, and dilution to $0 \cdot 1 \mu \mathrm{g} / \mathrm{ml}$. in $6 \times \mathrm{SSC}$, the DNA was loaded onto nitrocellulose filters (B6, $13 \mathrm{~mm}$ diameter, Schleicher and Schuell) by filtration according to Gillespie \& Spiegelman (1965). The filters were washed with 20 $\mathrm{ml}$. of $6 \times \mathrm{SSC}$, dried for several $\mathrm{hr}$ at room temperature and further dried for $4 \mathrm{hr}$ at $80^{\circ} \mathrm{C}$ under vacumm. The DNA loaded filters were incubated in stoppered glass vials for 
$16 \mathrm{hr}$ at $37^{\circ} \mathrm{C}$ in $0.6 \mathrm{ml}$. of $33 \%$ formamide $-2 \times \mathrm{SSC}$ containing the indicated amount of $\left[{ }^{3} \mathrm{H}\right]$ RNA. Two filters, a loaded one and an unloaded one, were incubated together in the same vial to provide a blank control. The filters were then rinsed in $33 \%$ formamide$2 \times \mathrm{SSC}$ and repeatedly in $2 \times \mathrm{SSC}$, before treatment with $50 \mu \mathrm{g} \mathrm{RNase} / \mathrm{ml}$. for $1 \mathrm{hr}$ at $37^{\circ} \mathrm{C}$ in $2 \times$ SSC.

The filters were washed on both sides with $20 \mathrm{ml}$. of $2 \times \mathrm{SSC}$, dried and counted in $10 \mathrm{ml}$. of scintillation solution (Beckman Fluoralloy) in a Beckman 200 counter. In identical experimental conditions, the loading efficiency of labeled mouse satellite DNA was over $92 \%$ and the loss of DNA from the filters during incubation did not exceed $10 \%$. Noise levels on unloaded filters were below $50 \mathrm{cts} / \mathrm{min}$.

\section{Results}

(a) Detection of $\beta$ fragments by buoyant-density centrifugation

When $D$. melanogaster nuclear DNA is extensively sheared by sonication to a single-strand molecular weight of 100 to 200,000 daltons, a class of highly reiterated sequences can be isolated on hydroxyapatite after renaturation for a $C_{0} t$ of $10^{-1}$ : these sequences, which we call h.a.r.r.DNA ( $h$ ydroxy-apatite isolated rapidly renaturing $D \mathrm{NA}$ ), have a homogeneous base composition and band in a $\mathrm{CsCl}$ gradient at a discrete density, $\rho=1.691 \mathrm{~g} / \mathrm{ml}$. (Botchan, Kram, Schmid \& Hearst, 1971 and Fig. 3(a)).

While representing 8 to $9 \%$ of the genome, a very small fraction, if any, of this

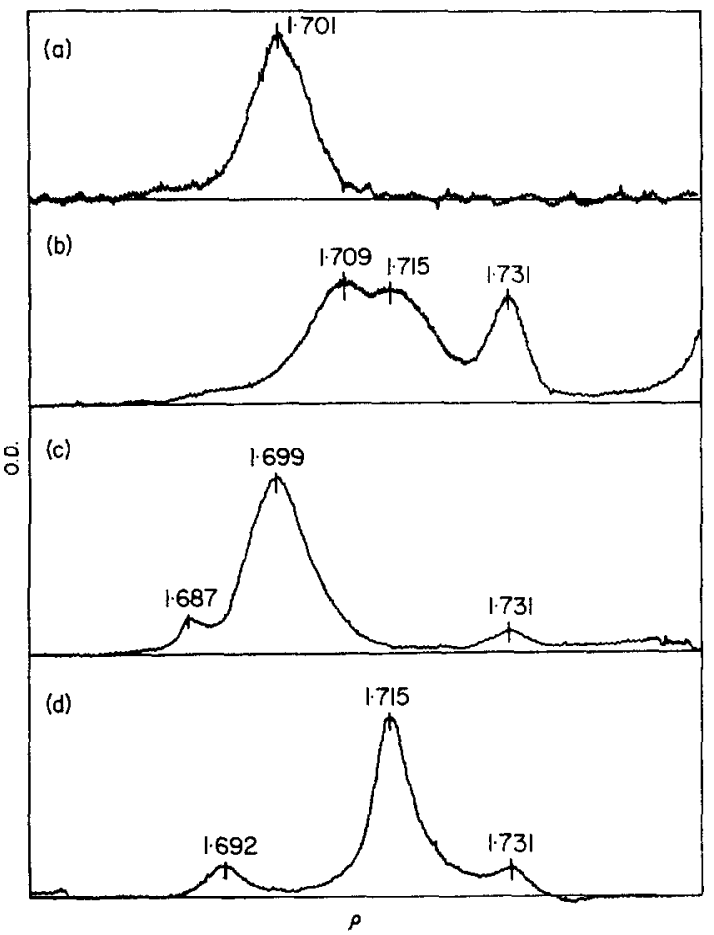

FIG. 2. Analytical centrifuge buoyant density profiles of (a) native D. melanogaster nuclear DNA; (b) $D$. melanogaster DNA renatured overnight $\left(C_{0} t=8\right)$; (c) native mouse nuclear DNA; (d) mouse DNA renatured overnight $\left(C_{0} t=10\right)$. D. melanogaster double strand $=15 \times 10^{6}$ daltons; single strand $=6 \times 10^{6}$ deltons. Mouse double strand $=10 \times 10^{8}$ daltons; single strand $=5 \times 10^{6}$ daltons. The peaks, with density $\rho=1.731 \mathrm{~g} / \mathrm{ml}$., represent marker DNA from Micrococcus lysodeikticus. 
material is resolved as a nuclear satellite (Fig. 2(a)). In mouse, hybridization experiments (Flamm, Walker \& McCallum, 1969a) between the satellite and the main band DNA have demonstrated that 10 to $20 \%$ of the satellite sequences are included in the main band, while most of them appear as a distinct satellite (Fig. 2(c)). Pieces of mouse satellite up to 20 to 40 million daltons have indeed been isolated (Bond, Flamm, Burr \& Bond, 1967). A procedure (Waring \& Britten, 1966) which results in a high resolution of the mouse satellite from the very partially renatured main band DNA consists in allowing the total mouse genome to reassociate overnight (Fig. 2(d)). When the same technique is applied to the $D$. melanogaster genome, the h.a.r.r.DNA sequences failed to show this resolution after renaturation for $C_{\mathrm{o}} t=0.5$ to a $C_{\mathrm{o}} t=10$ Fig. 2(b)).

In order to investigate the length and the distribution of the h.a.r.r.DNA sequences in the Drosophila genome, samples of nuclear DNA, sheared to different molecular weights, were denatured and allowed to renature at conditions which will only allow for reassociation of the previously characterized highly reiterated sequences. Since it is known that the rate of reassociation of single DNA strands is proportional to the square root of the fragment size (Wetmur \& Davidson, 1968; Wetmur, 1971), the appropriate $C_{0} t$ corrections were made. The renatured molecules were isolated on hydroxyapatite, eluted and banded in $\mathrm{CsCl}$. Because of the choice of a $C_{0} t$ appropriate only for reassociation of h.a.r.r.DNA sequences, the hydroxyapatite fractionation

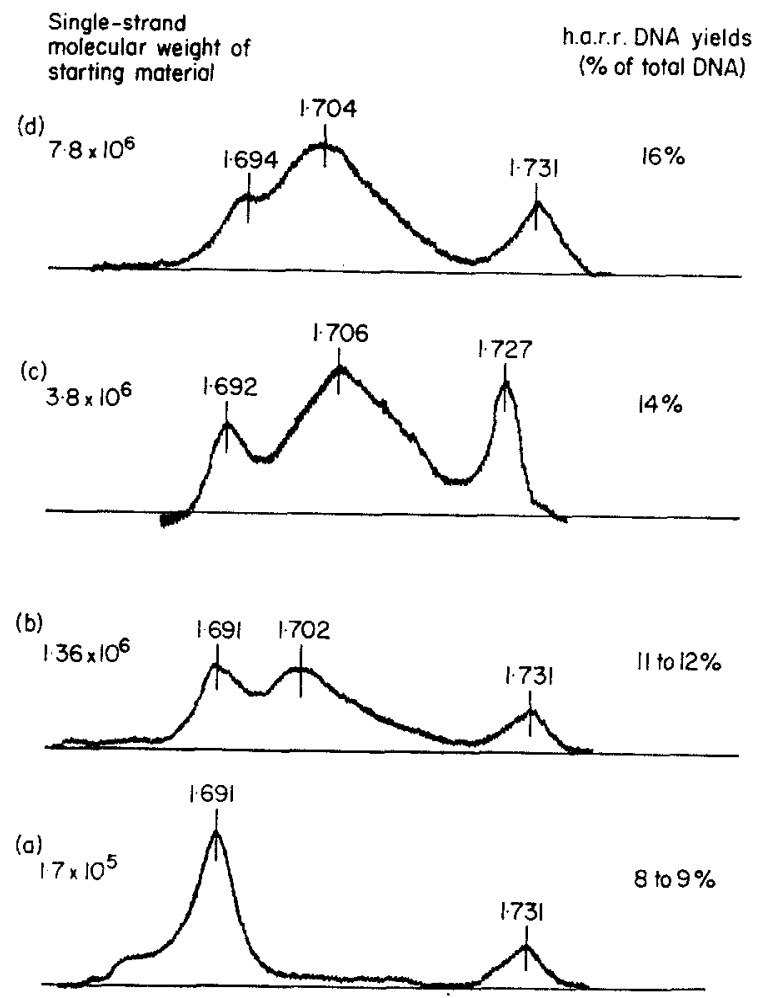

Fia. 3. Buoyant density profiles of hydroxyapatite-isolated rapidly-renaturing DNA from different molecular weights of the starting DNA preparation. Marker DNA's are $E$. coli $\left[{ }^{15} \mathrm{~N}\right] D N A$ $(\rho=1.727 \mathrm{~g} / \mathrm{ml}$.) and $M$. lysodeikticus DNA $(\rho=1.731 \mathrm{~g} / \mathrm{ml}$.). The hydroxyapatite fractionation was performed after renaturation for a $C_{0} t=10^{-1}$ for sample (a) and for appropriately corrected $C_{0} t$ values for the other samples es explained in the text. 
operated as a filter retaining those fragments with renatured h.a.r.r.DNA sequences, i.e. $\beta$ as well as $\alpha$ fragments. Cuts containing exclusively the presumed spacer sequences or other less redundant sequences of the non-chromocentric DNA are still completely denatured and do not bind to the hydroxyapatite.

The analytical ultracentrifuge traces (Fig. 3) show a distribution of the isolated material in two peaks: a light peak at densities slightly higher than that expected for pure h.a.r.r.DNA sequences obtained from extensively sheared nuclear DNA and a heavy one at densities of 1.702 to $\mathbf{1 \cdot 7 0 6}$. Other significant features observed, concomitantly with the increasing size of the DNA fragments before fractionation are:

(i) increase in the amount of DNA bound to hydroxyapatite at $0.18 \mathrm{M}-\mathrm{Na}^{+}$, with yields ranging from 8 to $16 \%$ over the range of molecular weights investigated;

(ii) shifts toward higher densities of the light peak with an increasing amount of trailing material on the heavy side of the second peak;

(iii) the ratio of the light peak to the heavy peak decreases dramatically.

The density of the heavy peak, which is significantly higher than that of the native unfractionated nuclear DNA, suggests that it contains partially renatured and denatured DNA molecules. As the renaturation conditions were set to allow only for renaturation of the highly reiterated DNA sequences, we propose the following interpretation for the bimodal buoyant density profile of the rapidly renaturing DNA isolated on hydroxyapatite. The light peak contains almost pure h.a.r.r.DNA sequences while the heary peak is composed of fragments which consist of renatured h.a.r.r.DNA sequences covalently linked to adjacent and/or intercalated spacer DNA segments, still unrenatured.

A qualitatively similar phenomenon is observed for the mouse h.a.r.r.DNA. The total nuclear DNA from mouse was denatured and renatured for a $C_{0} t$ of $10^{-2}$. The result of a $\mathrm{CsCl}$ banding of the material eluted from the hydroxyapatite is shown in Figure 4. When pure satellite is isolated and renatured for a $C_{0} t$ of $10^{-3}$ (to account for

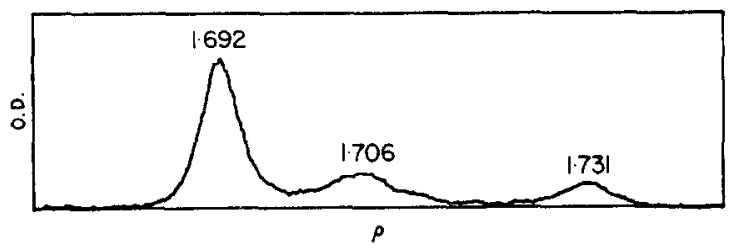

Fia. 4. Analytical contrifuge trace of the hydroxyapatite-isolated $\left(O_{0} t=10^{-2}\right)$ rapidly-renaturing DNA from mouse nuclear DNA at a single-strand molecular weight of 3 million.

its proportion in the total genome), it bands as a single peak. At the single strand molecular weight of 3 million there is a striking difference in the proportions of the light and heavy peaks, when compared to the $D$. melanogaster h.a.r.r.DNA obtained at a similar cut size (Fig. 3(c)).

Consistent with our interpretation is not only the observation of the double-peak phenomenon but also the concomitant increase in yield over the range of molecular weights investigated with the $D$. melanogaster genome. In the case of model A (Fig. 1), even for the largest cut size used $\left(7.8 \times 10^{6}\right.$, single strand mol. wt.), the maximal yield effect to be expected is an absolute increase of $0.2 \%$. Model B however implicates 
a yield dependence when the cut size approaches that of the $\alpha$ (pure h.a.r.r.DNA) segments. It is also clear that with increasing cut sizes the proportion of $\beta$ fragments must increase with respect to the $\alpha$ segments. Our interpretation of the bimodal buoyant density pattern thus assumes that the $\beta$ fragments constitute the heavy peak and are recovered after hydroxyapatite fractionation as partially denatured molecules. One alternative explanation is that this second peak represents renatured molecules from the next less redundant DNA families, without any direct topological relationship with h.a.r.r.DNA in the genome. We feel that this possibility can be ruled out by the $C_{0} t$ at which the fractionation was performed. Moreover, the corrections introduced, according to Wetmur \& Davidson (1968), are in our case conservative, since the correction involves a complete zippering of two single strands after a proper fit nucleation is made. For molecules only partially complementary, the match does not cover the entire fragment, so the length dependence must be less.

Also consistent with our interpretation are the melting curves in Figure 5, which

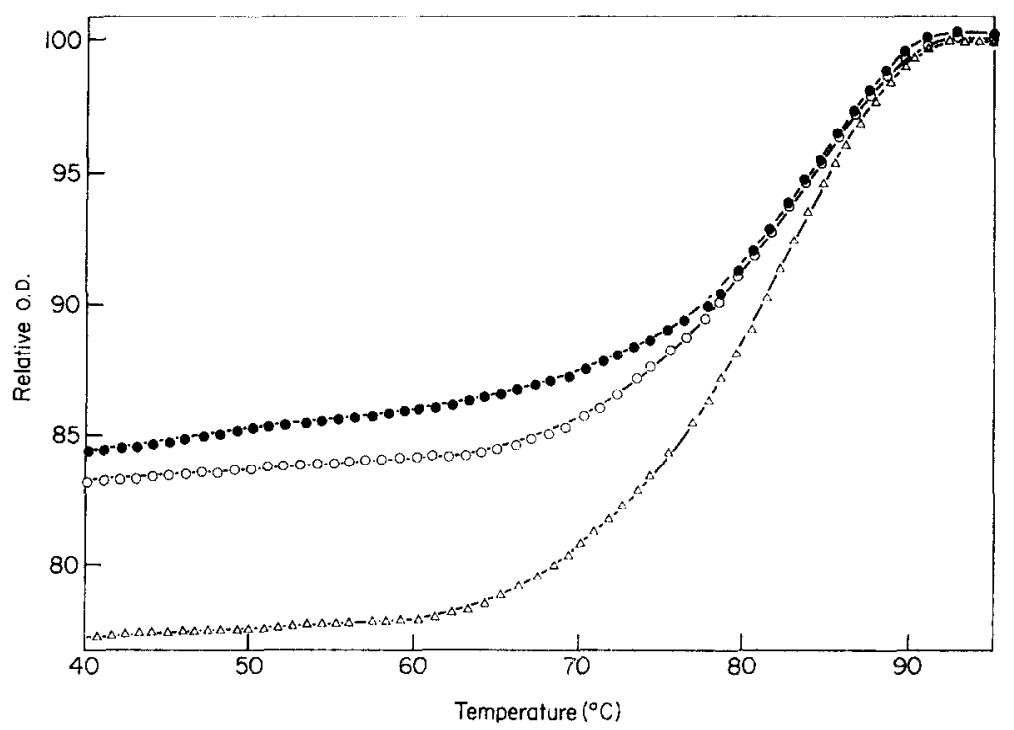

FIG. 5. Melting curves of h.a.r.r.DNA isolated from DNA preparations of different molecular weights. All samples were dialyzed against 0.12 M-phosphate buffer (pH 6.8), before meusurements. $-\triangle-\triangle-$, Single-strand mol. wt, $1.7 \times 10^{5} ;-\bigcirc-O-$, single-strand mol. wt, $1.36 \times 10^{6}$; - single-strand $\mathrm{mol}$. wt, $7.8 \times 10^{6}$.

present evidence that the amount of renatured material isolated at three different molecular weights decreases as the cut size increases. There is a reduction of hyperchromicity from $31.5 \%$ (for the material banded in Fig. 3(a)) to $20.5 \%$ and $19 \%$ for samples with banding patterns similar to those shown in Figure 3(b) and (d). The respective yields from the hydroxyapatite for the three specific samples, whose melting profiles are plotted in Figure 5, were $8 \%, 12 \%$ and $14 \%$. Assuming that all h.a.r.r.DNA sequences have been isolated in the two higher molecular weight samples, the reduction in hyperchromicity (from 100 to 65 and $60 \%$ ) is completely accounted for by their dilution (from 100 to 66 and $57 \%$ ) according to the yield data, with unrenatured sequences covalently linked to h.a.r.r.DNA. The covalent linkage is necessary to explain their retention on hydroxyapatite. 
(b) Evidence for $\beta$ fragments from kinetic and hybridization experiments

Another interpretation of a bimodal buoyant density pattern, which has been observed for renatured bacterial DNA (Schildkraut, Marmur \& Doty, 1961) is the following: due to heterogeneity in molecular weights, some h.a.r.r.DNA fragments will renature in perfect register while other molecules will be partially reassociated with single strand ends. In addition to the fact that this interpretation fails to provide an explanation for the increasing yields, we present evidence that the increasing yields reflect the recovery of non-h.a.r.r.DNA sequences linked to h.a.r.r.DNA.

This is first shown by measuring the kinetics of reassociation of the rapidly renaturing DNA isolated on hydroxyapatite at different molecular weights. We have reported (Botchan et al., 1971), that the pure h.a.r.r.DNA fractionated from extensively sheared nuclear DNA consists of two subclasses, representing 55 and $45 \%$ of it and with $C_{0} t_{0.5}$, respectively, $6 \times 10^{-4}$ and $2 \times 10^{-2}$. Half-renaturation of their mixture in h.a.r.r.DNA was attained at a $C_{0} t$ of $6 \times 10^{-3}$. Table 1 presents the fraction

\section{TABLE 1}

Reassociation of h.a.r.r.DNA isolated from DNA preparations of different molecular weights

\begin{tabular}{lcc}
\hline h.a.r.r.DNA analyzed & $\begin{array}{c}\% \text { Renaturation } \\
\text { at } C_{0} t=6 \times 10^{-3}\end{array}$ & $\begin{array}{c}\text { Yield from hydroxyapatite } \\
\text { (\% of unfractionated DNA) }\end{array}$ \\
\hline From DNA, 1.7 $\times 10^{5}$ & $\mathbf{5 1 . 2}$ & 8 \\
From DNA, $1.36 \times 10^{6}$ & 35.8 & 12 \\
From DNA, 3.8 $\times 10^{6}$ & $24 \cdot 0$ & 14 \\
From DNA, 7.8 $\times 10^{6}$ & 19.9 & 16 \\
\hline
\end{tabular}

The reassociation kinetics were measured as described in Materials and Methods (section d). The sizes of the starting preparations are expressed as single strand molecular weights.

renatured at this $C_{0} t$ value for the samples banded in Figure 3 . It should be pointed out that the reassociation kinetics were measured after shearing these samples to 100,000 daltons (single-strand molecular weight) in order to allow the h.a.r.r.DNA sequences to renature independently. The results clearly indicate an increasing dilution of h.a.r.r.DNA sequences with other sequences of higher complexities, in agreement with the dilution expected from the increasing yields of hydroxyapatite bound material.

Finally, our working hypothesis is supported by DNA-RNA membrane hybridization experiments (Table 2) in which $\left[{ }^{3} \mathrm{H}\right] \mathrm{RNA}$ synthesized in vitro from pure h.a.r.r. DNA was incubated with filters loaded with the following DNA preparations: pure h.a.r.r.DNA, h.a.r.r.DNA from high molecular weight nuclear DNA (Fig. 3(d)) and the purified heavy peak of the rapidly renatured fraction from the same high molecular weight DNA. Membranes loaded with the non-hydroxyapatite binding fraction from sonicated nuclear DNA, and thus containing all DNA sequences except those in h.a.r.r.DNA, were used as controls. The h.a.r.r.DNA from the high molecular weight DNA was $40 \%$ as efficient as pure h.a.r.r.DNA in good agreement with the dilution $(50 \%)$ of h.a.r.r.DNA sequences calculated from their respective yields. Furthermore, an important result is that $90 \%$ of the h.a.r.r.DNA sequence specific counts, which are complementary to the rapidly renaturing fraction isolated from the 


\section{TABLE 2}

Hybridization of pure h.a.r.r.DNA sequences to h.a.r.r.DNA isolated from $D N A$ preparations of different molecular weights

\begin{tabular}{lcccc} 
DNA on filter & $\begin{array}{c}\text { h.a.r.r.DNA } \\
\text { from } \\
\text { sonicated } \\
\text { DNA }\end{array}$ & $\begin{array}{c}\text { h.a.r.r.DNA } \\
\text { from high } \\
\text { mol. wt. } \\
\text { DNA } \\
\text { (both peaks) } \\
\text { Cts/min bound to filter }\end{array}$ & $\begin{array}{c}\text { Heavy peak } \\
\text { of h.a.r.r.DNA } \\
\text { from high mol. } \\
\text { wt. DNA }\end{array}$ & $\begin{array}{c}\text { Total DNA } \\
\text { with } \\
\text { h.a.r.r.DNA } \\
\text { removed }\end{array}$ \\
\hline $\begin{array}{l}{ }^{3} \text { H]RNA complementary to } \\
\text { h.a.r.r.DNA input }=2 \times 10^{4} \\
\text { ots/min/reaction }\end{array}$ & 1112 & 457 & 392 & 24 \\
$\begin{array}{l}{ }^{3} \text { H]RNA complementary to } \\
\text { h.a.r.r.DNA input }=10^{5} \\
\text { cts/min/reaction }\end{array}$ & 5590 & 2019 & 1894 & 104 \\
\hline
\end{tabular}

DNA-RNA hybridization was performed at $37^{\circ} \mathrm{C}$ in $0.6 \mathrm{ml} .2 \times \mathrm{SSC}, 30 \%$ formamide for $16 \mathrm{hr}$.

high molecular weight DNA, were also bound by its heavy peak. This indicates that this largely predominant heavy peak (see Fig. 3(d)) contains most of the renatured h.a.r.r.DNA sequences in $\beta$ fragments, i.e. covalently linked to DNA of unrelated nucleotide sequences.

\section{(c) Length and distribution of h.a.r.r.DNA and spacer segments}

In order to assign definite values for the relative lengths of h.a.r.r.DNA and spacer segments, we have programmed the computer to construct a series of $\mathrm{CsCl}$ banding patterns for different cut sizes. The experimental data suggest that the spacer sequences have a much lower redundancy than the very rapidly renaturing h.a.r.r.DNA although the model being investigated by computer-generated data does not require this to be true. The model only requires that the two types of sequences have some physical property which makes them separable. It is assumed that the sequences of h.a.r.r.DNA and spacer DNA are of definite lengths, $A$ and $B$. The physical technique used to separate these sequences is buoyant density: on the computer scale, the $A$ segments have a density $\rho_{A}=1$, and the $B$ segments have a density $\rho_{B}=2$.

Consider Figure 6 showing an arbitrary choice of $A$ and $B$, and an arbitrary cut size $L$. Given a defined distribution of cut sizes $L$ (we assume a Gaussian distribution of molecular weights in the initial DNA preparation), the computer program provides the answer for the distribution of densities obtained from such an arrangement of A and B, conditioned by the fact that only cuts containing some A sequences are retained by an appropriate fractionation procedure. Therefore, a cut size small relative to $A$ and $B$ produces almost exclusively $\alpha$ fragments (Fig. 6(a)), irrespective of the $A / B$ ratio. When the size of the fragments increase, $\beta^{\prime}$ fragments are also retained. The $\alpha$ fragments remain the predominant fraction until the cut size approaches the length of $A$ or $B$, whichever is smaller; then the proportion of $\alpha$ fragments drops sharply. For fragments longer than A or B (Fig. 6(c)), B" fragments with two interfaces start being produced. The $\beta^{\prime}$ fragments containing only one interface give a flat heavy tail in the density distribution extending to $\rho=2$, since the corresponding 
(a) Cut size $\angle$ « $A$ or $B$

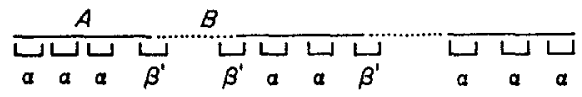

(b) Cut size $\angle$ close to $B$

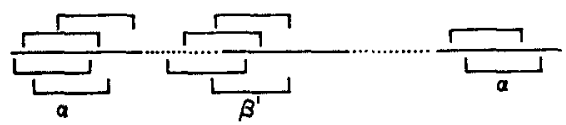

(c) $L, B$
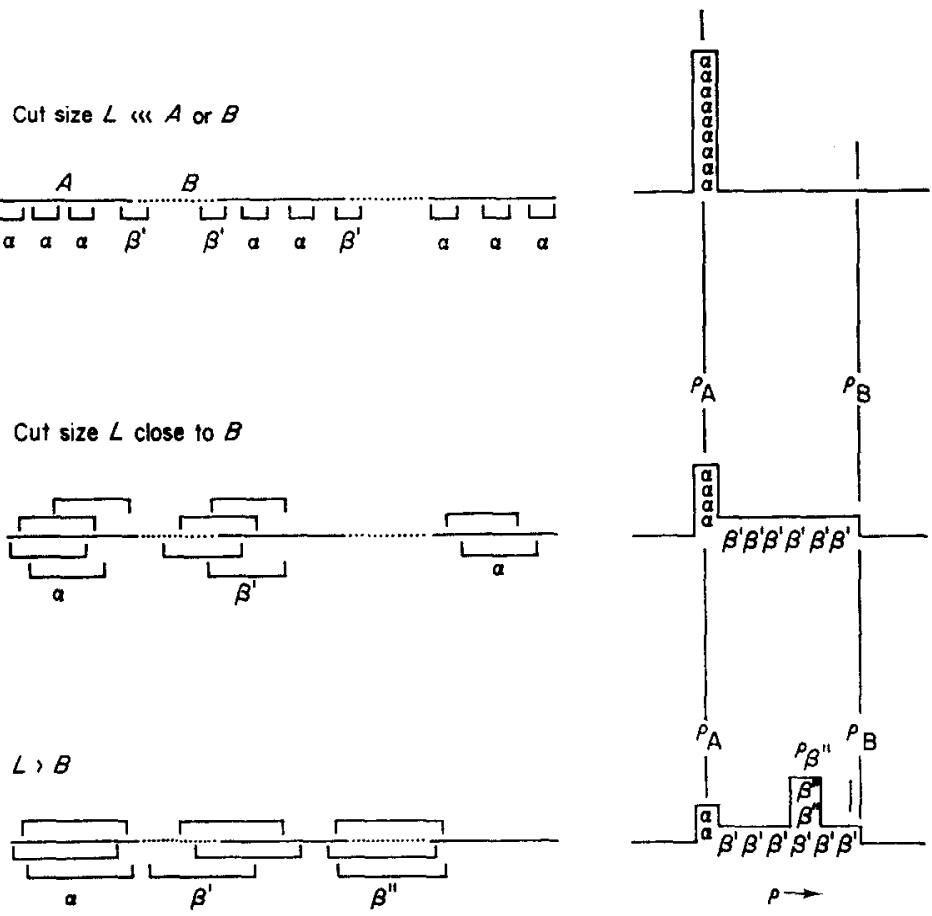

FIG. 6. Diagrammatic representation of density profiles generated by the computer simulated model. h.a.r.r.DNA and spacer sequences have arbitrary lengths $A$ and $B$ and densities $\rho_{A}$ and $\rho_{\mathrm{B}}$. Only fragments containing some h.a.r.r.DNA sequences are taken in consideration for the pure $B$ fragments are excluded by an appropriate fractionation procedure.

$\alpha=$ Pure h.a.r.r.DNA fragments; $\beta^{\prime}=$ fragments with one h.a.r.r.DNA-spacer interface; $\beta^{\prime \prime}=$ fragments with two interfaces.

cuts are equally probable. The $\beta^{\prime \prime}$ fragments, however, cause the second and heavy peak for there are many independent cuts of equal density in the fragments with two interfaces.

Figure 7 gives three representative series of computer-simulated profiles for the cases where $B>A, A>B$ and $A \gg B$ : it can be seen that the relative proportion of $\alpha$ and $\beta$ fragments is very sensitive to the relative lengths of the h.a.r.r.DNA and spacer sequences. Profiles comparable to those experimentally obtained for $D$. melanogaster (Fig. 3) are generated by the computer for $B=1, A=1$ to 3 . In this range of relative lengths, we point at the following features of the computer data to analyse the experimental buoyant density patterns. An average cut size equal to half the length of $B$ produces a predominant light peak with some trailing material at higher densities: this situation is experimentally encountered in Figure 3(a). When the average cut size reaches the length of $B$, the heavy peak starts appearing as in Figure 3 (b). For cut sizes greater than $2 \times B$, the light peak of $\alpha$ or pure h.a.r.r.DNA frag ments decreases very quickly, as observed in Figure 3(c) and (d).

The computer-generated double peak, however, persists over cut sizes from $L=1$ to $L=5$, whereas the experimental data show its persistence over a range of approximately 10. This can be accounted for by assuming that the real arrangement of h.a.r.r.DNA and spacer DNA sequences involves a distribution rather than a uniform definite length for the $\mathbf{A}$ and $\mathrm{B}$ segments. That is, by taking linear combinations of different simulated distributions, the experimental data can be fit. We tentatively 

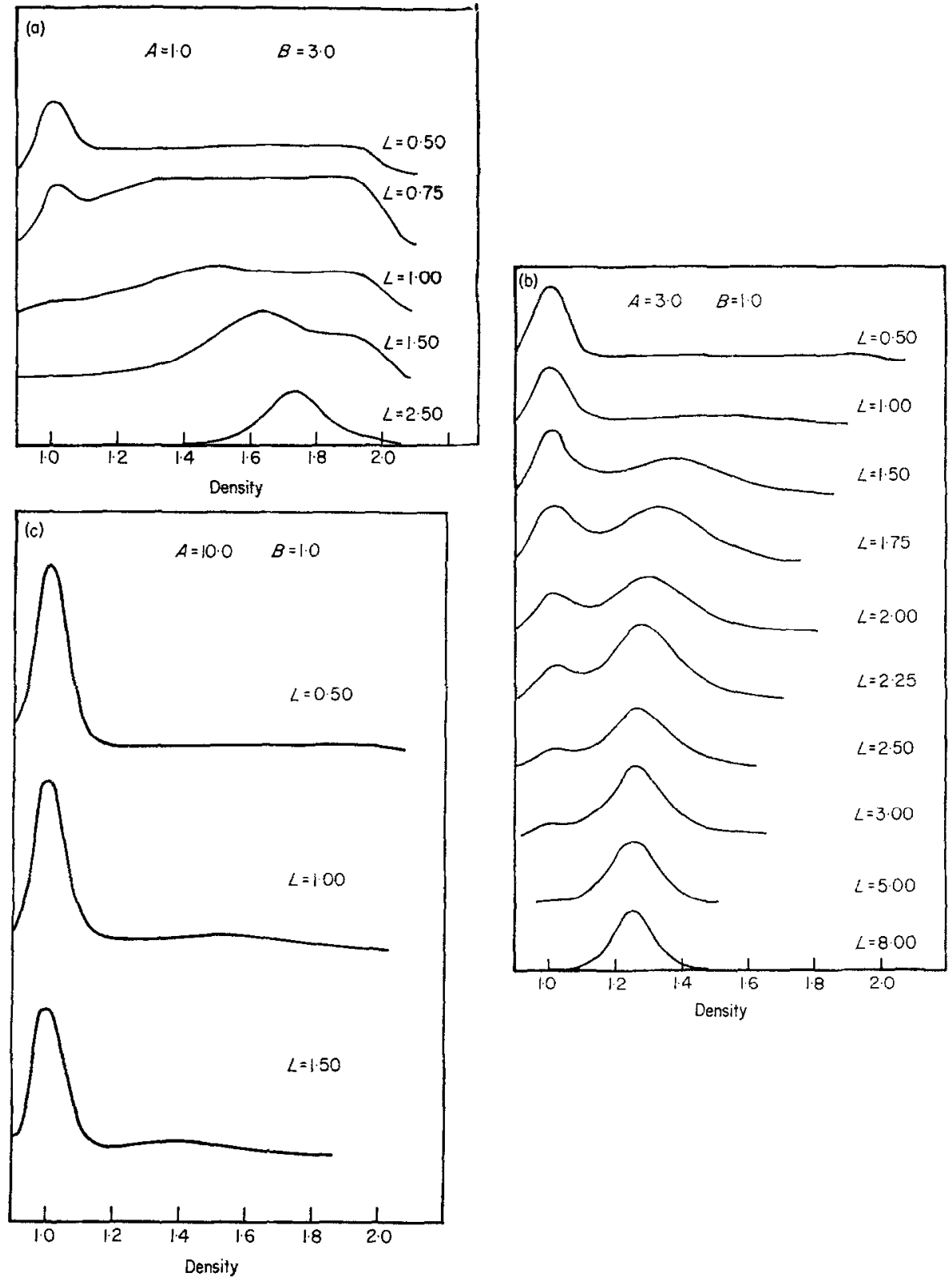

Fra. 7. Computer simulated profiles for (a) $A=1 B=3$ (b) $A=3 B=1$ (c) $A=10 B=1$. Cut sizes $(L)$ and the lengths $A$ and $B$ of h.a.r.r.DNA and spacer sequences are expressed in the same arbitrary units. In tho computer scale the $A$ segments have a density $\rho_{A}=1$ and the $B$ segments have a density $\rho_{\mathrm{B}}=2$.

assign to the spacers $(B)$ an average single strand molecular weight of 1 to 2 million daltons, or 3000 to 6000 nucleotides. The computer data suggest an $A / B$ ratio of 1 to 3 , whereas the experimental data are consistent with the following estimates: 0.7 to 0.8 from the kinetic and hybridization results, 1.0 to 1.3 from the yield increase, 1.5 from the reduction in hyperchromicity. Therefore, the single strand length of the h.a.r.r.DNA segments $(A)$ could range from 0.75 to 3 million daltons, or 2500 to 10,000 nucleotides long. 
It should be pointed out that the computer analysis does not take into account the denaturation and subsequent renaturation of the h.a.r.r.DNA sequences. This process randomizes the joined $A$ sequences, having an uncertain effect on the density distribution. It is highly likely from examining the size dependence of the double peak phenomenon that h.a.r.r.DNA and spacer do not come in definite lengths but in broad distribution of lengths. The depth of the present analysis does not allow us to be more quantitative at this point.

\section{Discussion}

We have investigated in the present work the arrangement of the highly reiterated DNA sequences concentrated in the centric heterochromatin of $D$. melanogaster and present evidence that this DNA comes in segments approximately 1.5 to 6 million daltons (double-strand molecular weight) which are spaced by a less redundant, variety of DNA in sequences approximately 2 to 4 million daltons. A qualitatively similar conclusion holds for the mouse genome, although, from preliminary data, there is a lower proportion of spacer relative to the length of the highly reiterated mouse satellite DNA segments. This conclusion does not contradict the recently presented evidence that isolated satellite does not contain spacer sequences (Pyeritz, Lee \& Thomas, 1971).

The finding that the molecular weight of the isolated satellites of the Drosophila hydei series reported by Hennig, Hennig \& Stein (1970) were always lower than the average main band DNA molecular weights points to a certain type of artifact when measuring the satellite content of an organism. If the molecular weight is too high, the satellite band can be poorly or not at all resolved, depending upon the spacing of the highly homogeneous satellite sequences by other DNA sequences of different $\mathrm{G}+\mathrm{C}$ content. Therefore, discrepancies in the literature regarding the resolution of nuclear satellite bands ought to be examined with respect to molecular weights of the different materials.

Another, biologically more significant, cause for the possible variation in satellite contents could result from the loss or the relative amplification of specific DNA sequences in differentiated tissues (Krueger \& McCarthy, 1970) in cells selected in vitro (Maio, 1971) or at a particular stage of development (Brown \& Dawid, 1968). In Drosophila, cytological observations (Rudkin, 1969), "in situ hybridization" of h.a.r.r.DNA to the salivary giant chromosomes (Botchan et al., 1971) and renaturation studies of the polytene chromosome DNA (Dickson, Boyd \& Laird, 1971) indicate that during polytenization the centric heterochromatin does not replicate to the same extent as do the euchromatic regions.

The evidence presented here for the interspersion of spacer sequences within the highly repetitious DNA of the centric heterochromatin raises two interesting and not necessarily exclusive possibilities. In terms of housekeeping and dynamics of chromosomes during mitosis and meiosis, the highly reiterated DNA sequences may provide the necessary element for a common need on different chromosomes, i.e. chromosome bulk around the centromere (Walker, 1971) or a particular type of helical configuration required for centrometric structure or activity. The centromeric regions are often implicated in pairing of homologous chromosomes at meiosis (Darlington, 1935; La Cour \& Wells, 1970). The spacer segments, with more sequence diversity, represent another constituent of the centric heterochromatin, more likely to mediate any process which requires specific recognition. 
Constitutive heterochromatin is believed to be inactive with respect to RNA transcription. The scarcity of markers in this region of Drosophila chromosomes, the occurrence of numerous repeats of a simple sequence and its under-replication in endomitotic polytenic cells are consistent with this notion. Furthermore, the extremely low cross-over frequencies between markers proximal to opposite ends of this region indicate another sort of genetic isolation. Not inconsistent with the suggestion (Southern, 1970) that the simplicity of the centromeric heterochromatin highlyredundant DNA sequences would render unlikely any informational content for it, the interspersed DNA sequences could bear genetic information and we refer to them as spacer only for convenience. The interspersion of these spacers among a genetically inert DNA, however, raises the possibility of an arrangement for important genes as in the nucleolus. During gene amplification of the ribosomal cistrons, this region of the genome appears to be controlled by a separate replication system. Walker (1971) has suggested that satellite sequences may arise from gene duplication of part of the ribosomal spacer sequences; perhaps the satellite type sequences in the centric heterochromatin are now spacing important genes. The expression of centromeric heterochromatic DNA is still a matter of controversy. Flamm et al. (1969a) could not detect in different mouse tissues any significant amount of RNA complementary to the isolated satellite DNA. Harel, Hanania, Tapiero \& Harel (1968), however, have presented some evidence that mouse satellite is transcribed, perhaps these satellite sequences were not freed of the interspersed spacer segments. Cytological differences in the state of condensation of the constitutive heterochromatin have been observed in various tissues of the same organism, suggesting differences in its expression (Schmid, 1967) $\uparrow$

The constitutive heterochromatin is also biologically characterized by its late replication, and this holds at the molecular level for the satellite DNA of mouse (Tobia, Schildkraut \& Maio, 1970; Flamm, Bernheim \& Brubaker, 1971; Bostock \& Prescott, 1971).

The physical association with this late replicating DNA of other types of sequences possibly bearing informational content could provide the mechanism for their coordinated expression at the end of the cell cycle, in relation with the onset of mitosis. Surprisingly, in confluent mouse cells infected by polyoma virus, the replication pattern is reversed. The satellite replication proceeds in a synchronous wave some 12 hours before the onset of the bulk DNA. Evidence presented by Fox, Sheppard \& Burger (1971) indicates that the expression of certain genes before mitosis is a necessary prerequisite for cell surface changes occurring briefly during mitosis and presumably involved in the induction of the next round of DNA synthesis and cell division. These findings may provide a clue for why the replication pattern of satellite is reversed by polyoma infection. Perhaps in order to initiate DNA synthesis in the host cell some viral product must first induce the expression of host genes that are normally expressed at the end of the cell cycle.

We thank Eric Beals for assistance with the computer analyses and Peter Botchan for $E$. coli RNA polymerase. The research was supported in part by grants no. GM 11180 and GM 15661 of the National Institutes of Health. One of us (M. B.) was supported by a National Institutes of Health predoctoral biophysics training grant. 


\section{REFERENCES}

Birnstiel, M., Speirs, J., Purdom, I., Jones, K. \& Loening, U.E. (1968). Nature, 219, 454. Bond, H. E.; Flamm, W. G., Burr, H.E. \& Bond, S. B. (1967). J. Mol. Biol. $27,289$.

Bostock, C. J. \& Prescott, D. (1971). Exp. Cell Res. 64, 481.

Botchan, M., Kram, R., Schmid, C. W.\& Hearst, J. E. (1971). Proc. Nat. Acad. Sci., Wash., 68, 1125 .

Brown, D. D. \& Dawid, I. B. (1968). Science, 160, 272.

Burgess, R. R. (1969). J. Biol. Chem. 244, 6160.

Darlington, C. D. (1935). Proc. R. Soc, B. 118, 33.

Dickson, E., Boyd, J. B. \& Laird, C. D. (1971). J. Mol. Biol. $61,615$.

Flamm, W. G., Bernheim, N. J. \& Brubaker, P. (1971). Exp. Cell Res. 64, 97.

Flamm, W. G., Walker, P. M. B. \& McCallum, M. (1969a). J. Mol. Biol. 40, 423.

Flamm, W. G., Walker, P. M. B. \& McCallum, M. (1969b). J. Mol. Biol. 42, 441.

Fox, T. O., Sheppard, J. R. \& Burger, M. M. (1971). Proc. Nat. Acad. Sci., Wash., 68, 244. Gillespie, D. \& Spiegelman, S. (1965). J. Mol. Biol. 12, 829.

Gray, H. B., Jr. \& Hearst, J. E. (1968). J. Mol. Biol. 35, 111.

Harel, J., Hanania, N., Tapiero, H. \& Harel, L. (1968). Biochem. Biophys. Res. Comm. $33,696$.

Hennig, W., Hennig, I. \& Stein, H. (1970). Chromosoma, 32, 31.

Jones, K. W. \& Robertson, F. W. (1970). Chromosoma, 31, 331.

Krueger, R. G. \& McCarthy, B. J. (1970). Biochem. Biophys. Res. Comm. 41, 994.

La Cour, L. F. \& Wells, B. (1970). J. Cell Sci. 6, 655.

Maio, J. J. (1971). J. Mol. Biol. 56, 579.

Pardue, M. L. \& Gall, J. G. (1970). Science, 168, 1356.

Pyeritz, R. E., Lee, C. S. \& Thomas, C. A., Jr. (1971). Chromosoma, in the press.

Rae, P. M. M. (1970). Proc. Nat. Acad. Sci., Wash., 67, 1018.

Rao, P. N. \& Johnson, R. T. (1970). Nature, 225, 159.

Ritossa, F. M. \& Spiegelman, S. (1965). Proc. Nat. Acad. Sci., Wash., 53, 737.

Rudkin, G. T. (1969). Genetics, 61, 227.

Schildkraut, C. L., Marmur, J. \& Doty, P. (1961). J. Mol. Biol. 3, 595.

Schmid, C. W. \& Hearst, J. E. (1971). Biopolymers, 10, 1901.

Schmid, W. (1967). Arch. Klaus-Stift. Vererbforsh. 42, 1.

Smith, B. J. (1970). J. Mol. Biol. 47, 101.

Southern, E. M. (1970). Nature, 227, 794.

Studier, F. W. (1965). J. Mol. Biol. 11, 373.

Tobia, A. M., Schildkraut, C. L. \& Maio, J. J. (1970). J. Mol. Biol. 54, 499.

Votavova, H., Sponar, J. \& Sormova, Z. (1970). Europ. J. Biochem. 12, 208.

Walker, P. M. B. (1971). Nature, 229, 306.

Waring, M. \& Britten, R. J. (1966). Science. 154, 791.

Wetmur, J. G. (1971). Biopolymers, 10, 601.

Wetmur, J. G. \& Davidson, N. (1968). J. Mol. Biol. 31, 349.

Note added in proof: Total D. melanogaster DNA contains three "satellite" peaks in CsCl density gradients $\rho=1 \cdot 675, \rho=1 \cdot 680, \rho=1 \cdot 687$. These peaks were not present in our nuclear DNA preparations with molecular weights ranging from $10 \times 10^{6}$ daltons to $30 \times 10^{6}$ daltons. D. melanogaster mitochondrial DNA can be isolated and shown to be circular 5.3 micron structures banding at $\rho=1.680$ (Botchan \& Dorman, unpublished observations). The 1.687 satellite at certain molecular weights must contain some of the h.a.r.r.DNA sequences sheared away from the spacers. This satellite is composed of two components as judged by melting profiles and alkaline $\mathrm{CsCl}$ gradients (Gall, J. G., Cohen, E. H. \& Polan, M. L., Chromosoma, 33, 319 (1971) and Botchan, unpublished observations). Only one of these components can be shown to be cryptically present in the main band. We do not know what the origin of the other component under the 1.687 satellite is, although it can bo seen as the major component of total DNA from unfertilized eggs. 